\title{
Forensic Engineering helps in Accident Cases Analysis: A Review
}

Sharma $\mathbf{M}^{1^{*}}$, Mishra RK${ }^{1}$, Sharma $\mathrm{DK}^{1}$ and Tiwari $\mathbf{R S}^{2}$

${ }^{1}$ State Forensic Science Laboratory, Rajasthan Jaipur-302 016, India

2 Poornima College of Engineering (PCE), Sitapura Industrial Area, Rajasthan Jaipur-302 022, India

Corresponding author: Mukesh Sharma, State Forensic Science Laboratory, Rajasthan Jaipur-302 016 India, Tel: 9951012146 ; E-mail: mksphy@gmail.com

Received date: August 26, 2017; Accepted date: September 27, 2017; Published date: October 10, 2017

Copyright: ( 2017 Sharma M, et al. This is an open-access article distributed under the terms of the Creative Commons Attribution License, which permits unrestricted use, distribution, and reproduction in any medium, provided the original author and source are credited.

\begin{abstract}
In accident cases are always an important and hurdle for investigating agency when is it doubt which are generally arise from the violation of statutes that typically require the driver of an automobile involved in an accident to stop, identify himself and his vehicle and render aid to persons injured in the accident. We, through this present study, have tried to explain the importance of the spot examination and preservation of the scene of crime in accident cases, which are generally avoided while investigation of accident cases in India.

Through this paper, the author tried to explain the circumstances can change the view of the public as well as the investigating agency, by using the forensic expert view and opinion, proper examination of vehicles (in hit-n-run case or direct impact or side by side collision), victim's injury and scene of crime (spot of occurrence) and by-standers. We have reported three types of accident cases easier approach as 1-2-3 steps for accident cases analysis, which provide the forensic community a hands-on for accident investigation.
\end{abstract}

Keywords Crime scene investigation; Accident analysis; Trace evidence

\section{Introduction}

In India, police accident reports are often the main source of data for accident investigations. These reports usually contain information on traffic conditions, vehicle performance, road environment, driver characteristics, casualty demographics, and injury severity level. When comparing police reports with hospital records, the degree of the under-reporting of road casualties has been found to be quite significant. Casualty demographics, time of injury, hospital admission, and mode of transport, vehicle class, and car occupancy are all contributory factors to the reporting rate in police accident records. Fatal accidents are normally assumed to be reported in full. However, the degree of under-reporting is greater for less seriously injured casualties. The quality of police accident reports has also been examined in relation to the accuracy of accident attributes, vehicle performance, driver characteristics, and accident causes. Police data on the number of casualties involved and the time and location of accidents have been found to be unreliable in Rajasthan, India [1,2]. Importantly this article motive is mainly three folded: a) to provide easier steps of investigation in accident analysis; b) on the basis of our experience and knowledge one have summarized the literature in single article and c) mainly forensic investigation is needed in when homicide is tried to be created as an accident case, through this article, reader can easily adopt a right step of investigation.

\section{Methodology}

Through this paper, very interesting study being communicated for the awareness of the forensic scientific community that vehicles, victim's injury, scene of occurrence and concept of forensic engineering (direction and probability of vehicle path) can hold the clues to solve cases related to accident analysis. In this paper, we have also reported a general methodology to examine an accident vehicle and road accidents for a crime scene investigator as published by one of the author earlier in Figure 1 [2].

Investigation of cause of death is very important and need special attention and training. Protection of crime scene is very important for the investigation of crime scene. Observe persons, vehicles events, potential evidence and environmental conditions. Safety and wellbeing of officers and other individuals should be first priority $[3,4]$. Identify and control any dangerous situations or persons.

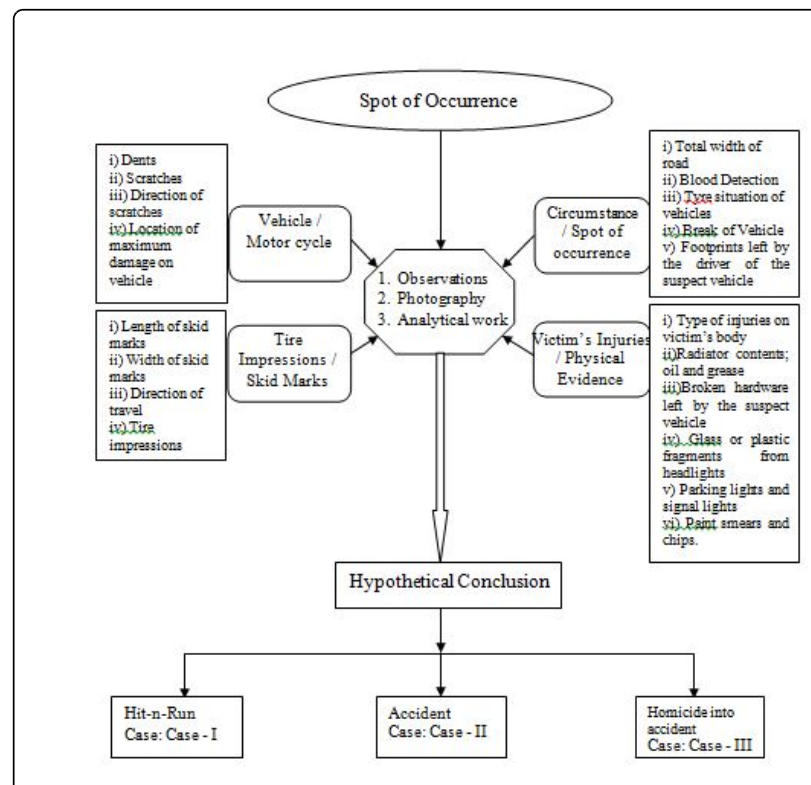

Figure 1: The methodology to examine an accident crime scene [2]. 


\section{Discussions}

Unfortunately, thousands of accidents happen every day. At the core of most of these accidents is the failure of something-a person, a product or an area to work or react properly. Categories of accidents include: product liability; vehicular accidents; third-party liability; construction site accidents; animal-involved accidents; maritime accidents; and many more. These categories can also have subcategories. For example, vehicular accidents include motorcycle accidents. Basic investigative procedures include: defining events that led to the accident; interviewing victims and/or witnesses; preparing photographs and sketches; and preparing reports. Investigators also apply different procedures depending on the type of accident. For example, an investigator will research an animal's history of violence in an animal-attack case. Physical impairment might cause accident like poor eyesight and/or physical impairment, with many jurisdictions setting simple sight tests and/or requiring appropriate vehicle modifications before being allowed to drive. Some time old age might have become a cause of accident so some jurisdictions requiring driver retesting for reaction speed and eyesight after a certain age $[5,6]$.

\section{1-2-3 STEPs to investigate hit-n-run Case [7]}

1) Vehicle of the victim always be at the spot of occurrence or at Police station should be examined thoroughly a) Level of Damages; b) Direction of impact; c) Angle of collision at spot; d) foreign material adhered to the victims vehicle or cloths.

2) Suspected Vehicles (one or more than one) should be examined thoroughly and try to reconstruct the possibilities of accident, to ruled out any wrong concept and to add or substrate the presence or absence of vehicle (driver/co-driver/other involved in case) by using mobile phone tower location might be very helpful for investigating purposes.

3) Victim's injury (purely medico-legal) might be helpful to trace the right path of investigations.

\section{1-2-3 STEPs to investigate a head-on-collision [8]}

1) In this types of cases both the vehicles are present at the spot or at the nearest police station; Both the Vehicles should be examined thoroughly as per flow chart shown in Figure 1.

2) Involvement of vehicle should be studied and try to reconstruct the possibilities of accident. Also try to find the scientific reason of the vehicle, by asking for motor vehicle experts, to check any failure or damage (like brake fail, tyre blast or engine chock or leakage of petrol etc.). To check the drivers faults alcohol and blood test in quite important for investigating purposes.

3) Sometime circumstantial reason (like any domestic animal on the highways, road light failure or unavailable, speed limits and sharp turns sign boards are not presented) might play a role of villain in accident cases.

\section{1-2-3 STEPs of Murder converted in to Accident [7,9]}

1) These are most typical to investigate as a forensic expert, most important evidences we find at the scene of occurrence and secondary scene of occurrence where this happening have been reported.

2) Secondly, the reporting person and the first respondent of this case, plays a vital role in investigation, some time story being modified as the investigation progressed.
3) Vehicle, victim's body and types of injury are very important in these cases.

\section{Conclusions}

The cases of accident and collision (motor vehicle collision, motor vehicle accident, car accident, or car crash) may result in injury, property damage, and death. A number of factors contribute to the risk of collision including; vehicle design, speed of operation, road design, and driver impairment. Worldwide motor vehicle collisions lead to significant death and disability as well as significant financial costs to both society and the individual.

It is essential that these crimes be solved in order to serve the victims and their families with justice. Moreover, there should be zeal to solve the crime. In this paper we have reported all types of accident cases should be examined as suggested 1-2-3 steps for each types of accident investigation. Where as in India, investigating agency are taking very lightly as the case of accident related, but sometime these investigation lead to different results and forensic investigation of these cold cases plays a vital role to solve or get the proper direction of investigations. Forensic engineering reveals that dent, broken pieces, scratches direction and scratches on the vehicles provide proper evidence of accident. This article provide a hands-on to the reader, forensic investigation of accident cases.

\section{Acknowledgement}

One of the authors (MS) is thankful to Prof. B L Ahuja, Dean Faculty of Science, M L Sukhadia University, Udaipur (Raj.), India for fruitful discussion and guidance. The partial work of the article has been presented in the National Level Conference in India.

\section{Reference}

1. Booklet issued monthly recorded crime (Crime Branch), Rajasthan, India June 2009.

2. Sharma M, Clemens D (2010) Sometimes the accident vehicle tells the story: A forensic case study.

3. Kiely TF (2005) Forensic Evidence: Science and the criminal law (2nd edtn.) CRC Press, Florida, USA.

4. Adams TF, Krutsinger J (2000) Crime Scene Investigation Prentice Hall.

5. Domke, Ellen, Klepitsch J (1993) Hit-Run: A Crash Course; 120a-Day in Chicago: Problem in Suburbs: Chicago Sun Times.

6. Vallejo CA, Edsicker D (2001) Crime Scene Investigation and Physical Evidence Manual.

7. Sharma M, Jha S, Mathur VN (2011) What can an accident explain: A forensic case study. Indian J of Forensic Medicine and Toxicology 5: 63-65.

8. Sharma M, Jain P, Singh P, Jha S, Tee K F (2014) Forensic engineering analysis of accidents in India: A Systematic Approach. CBI Bulletin 22: 14-21.

9. Sharma M, Jha S (2012) Forensic examination of hit-n-run cases: A study proc. of First International Conference on Law and Forensic 243-249. 